\title{
Uma proposta didática para o estudo da interação magnética entre ímãs e algumas considerações epistemológicas
}

A didactic proposal for the study of magnetic interaction between magnets and some epistemological considerations

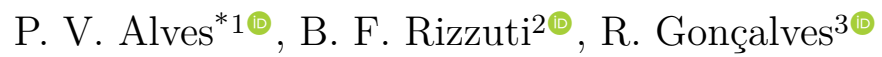 \\ ${ }^{1}$ Universidade Federal do Amazonas, Instituto de Educação, Agricultura e Ambiente, Humaitá, AM, Brasil. \\ ${ }^{2}$ Universidade Federal de Juiz de Fora, Instituto de Ciências Exatas, Departamento de Física, Juiz de Fora, MG, Brasil. \\ ${ }^{3}$ Centro de Educação de Jovens e Adultos Professora Jacira Caboclo de Costa, Secretaria de Estado de Educação e Desporto, \\ Manaus, AM, Brasil.
}

Recebido em 13 de Julho de 2020. Revisado em 30 de Julho de 2020. Aceito em 18 de Agosto de 2020.

\begin{abstract}
A força de interação magnética entre ímãs é um efeito curioso, que prende a atenção de pessoas das mais variadas faixas etárias. Se por um lado, sua descrição é pesada demais para ser apresentada em cursos de física básica, por outro, restringindo alguns aspectos dos magnetos, a força admite um comportamento descrito analiticamente por um decaimento exponencial com a distância entre os ímãs. Apresentamos, então, neste trabalho uma sequência de experimentos que nos permite estimar a força de repulsão entre pares de ímãs cilíndricos iguais. Esquecendo por um momento este lado pragmático, discutimos também como um campo magnético admite ser representado por um campo de vetores axiais.
\end{abstract}

Palavras-chave: Campo magnético, Força de interação entre ímãs, Atividades experimentais.

The force of magnetic interaction between magnets is a curious effect, which attracts the attention of people of the most varied ages. If, on the one hand, its description is too tricky to be presented in basic physics courses, on the other, restricting some aspects of the magnets, the force admits a behavior described analytically by an exponential decay with the distance between the magnets. We present, then, a sequence of experiments that allows us to estimate the repulsion force between pairs of equal cylindrical magnets. Forgetting for a while this pragmatic side, we also discuss how a magnetic field admits its representation as an axial vector field.

Keywords: Magnetic field, Interaction force between magnets, Experimental activities.

\section{Introdução}

Quando abrimos os livros padrões de eletromagnetismo [1] 3], nos deparamos com uma das partes da força de Lorentz,

$$
\vec{F}=q \vec{v} \times \vec{B} .
$$

A interpretação para esta expressão é a seguinte: uma partícula com carga $q$ e velocidade $\vec{v}$ sente uma força $\vec{F}$ quando a região espacial em que ela está é permeada por um campo magnético $\vec{B}$.

O primeiro ponto curioso é que se apelarmos para o princípio da relatividade, em que as leis da física são as mesmas em qualquer referencial [4],5], então escrevemos (1) no referencial que desloca-se junto com a partícula. Nesse caso, a força sobre a partícula seria nula pois sua velocidade é nula. A única origem física para uma força sobre uma partícula carregada parada (em determinado referencial) seria oriunda de um campo elétrico.

*Endereço de correspondência: periclesmat@ufam.edu.br
Assim, intuitivamente entendemos o caráter relativístico do eletromagnetismo. Eletrostática e magnetismo são manifestações que são unificadas em uma grandeza só, o campo eletromagnético. Veja a discussão no volume 2 do clássico Lectures on Physics, do Prof. Feynman [6] .

Gostaríamos de nos ater aqui, contudo, em outros dois pontos. O primeiro deles está ligado com uma reinterpretação para a expressão (1): será que podemos, de fato, chamar o campo magnético de um vetor? Nossas considerações vão mostrar que o campo magnético é quase um vetor. Ele apresenta praticamente todas as propriedades para que assim o possamos chamar. Este é o setor deste trabalho que caracterizamos como epistemológico. Partiremos da experimentação para mostrar como podemos justificar como campos magnéticos admitem uma representação vetorial usando a simples observação e argumentos físicos e matemáticos. Tal exposição, embora fundamental, é pouco usual na literatura, de modo que sua popularização é justificada. 
O outro ponto que será abordado, de maneira independente do primeiro mencionado acima, está ligado com um dos efeitos mais marcantes do magnetismo e pouco discutido em nível básico. Qual a força um ímã faz sobre outro? Esse problema parece trivial, mas expor considerações quantitativas não é uma tarefa imediata. E curiosamente, a literatura não a faz. Sempre nos deparamos com uma dicotomia usual na teoria de campo eletromagnético $\cdots$ partícula carregada/corrente elétrica gera campo $\cdots$ campo faz força sobre partícula carregada/corrente. Mas o efeito aparentemente intrigante, que prende a atenção mesmo de crianças, lida diretamente com a interação campo/campo, por exemplo, com uma bússola imersa no campo magnético terrestre. Essa foi a primeira memória científica de Albert Einstein [7], quando seu pai lhe deu uma bússola, mostrando o seu comportamento:

That this needle behaved in such a determined way did not at all fit into the nature of events... in the unconscious world of concepts. I can still remember - or at least I believe I can remember - that this experience made a deep and lasting impression on me. Something deeply hidden had to be behind things...

Deixando esta nota histórica de lado, podemos também endereçar o problema da força entre ímãs a questões mais técnicas e pragmáticas. Uma série de aplicações modernas, como a microeletrônica, a utiliza (por razões distintas; entre elas está o alcance maior do que em efeitos eletrostáticos): relés [8], atuadores [9], sensores magnéticos e etc [10]. Assim, apresentar tais efeitos já nos laboratórios de física básica, como uma atividade que forneça uma descrição analítica correspondente é também parte dos objetivos deste artigo.

Dito isso, dividiremos nosso trabalho da seguinte maneira. Na próxima Seção, mostraremos uma justificativa teórico-experimental para a representação vetorial de campos magnéticos. Na Seção 3, mostramos como estimar explicitamente forças entre ímãs. Mostraremos como para o caso particular de ímãs cilíndricos, a força entre os mesmos admite uma representação de um decaimento exponencial com a distância, em concordância com a representação analítica apresentada na literatura. Na sequência, apresentamos uma sequência de experimentos com o objetivo de estimar a força entre ímãs, fornecendo materiais, métodos, procedimento experimental e validação estatística. Em 5, os resultados são discutidos e a Seção 6é dedica às conclusões.

Usaremos a notação $\vec{a} \in \mathbb{A}$ para representar um vetor pertencente ao espaço vetorial correspondente. Todas as imagens que não possuírem fonte explícita, foram fotografadas/editadas pelos autores.

\section{Representação Vetorial para o Campo Magnético}

Como já mencionado anteriormente, começamos essa Seção com o seguinte questionamento: o campo magnético é de fato um vetor? Vamos mostrar, com as nossas próximas considerações, que a expressão (1), contendo um produto vetorial, pode ser deduzida a partir da experimentação. A ideia é jogar um feixe de partículas carregadas sobre um material que emite luz ao ser excitado pelas partículas. Podemos, dessa maneira, aproximar um ímã da superfície excitada e ver o que ocorre com o feixe. O esquema experimental é exibido na Figura 1 e foi montado pelo Prof. Bernhard Lesche na Universidade Federal de Juiz de Fora para utilização como ferramenta didática em aulas de demonstração investigativa. Os detalhes do aparato podem ser vistos em [11].

Não é nosso intuito aqui discutir detalhes da montagem. Efetivamente, temos uma fonte de alta tensão, conectada a duas placas circulares espaçadas, que formam uma região espacial com diferença de potencial. As placas estão em uma ampola com gás rarefeito. Uma das placas é conectada ao terminal positivo da fonte e contém um orifício que direciona partículas carregadas negativamente até um anteparo. O anteparo é coberto com um material que emite luz ao ser excitado pelas partículas carregadas que o atingem (Figura 1- (a)). Por fim, aproxima-se o ímã do anteparo, defletindo o feixe (Figura 1- (b)). Antes de seguirmos adiante, gostaríamos de tecer um breve comentário histórico. $\mathrm{O}$ aparato experimental nada mais é que uma versão moderna do tubo de Thomson ou ampola de Crookes. Ele foi utilizado por J. J. Thomson no seu famoso trabalho [12], na esperança de entender a natureza dos raios catódicos. Curiosamente, à época, creditava-se tais efeitos a algum processo do

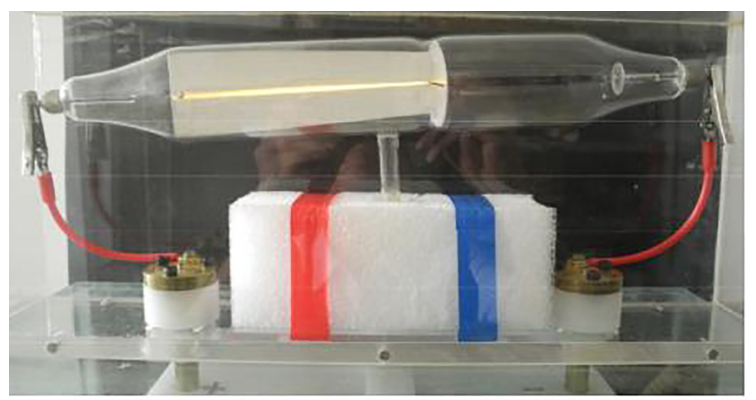

(a)

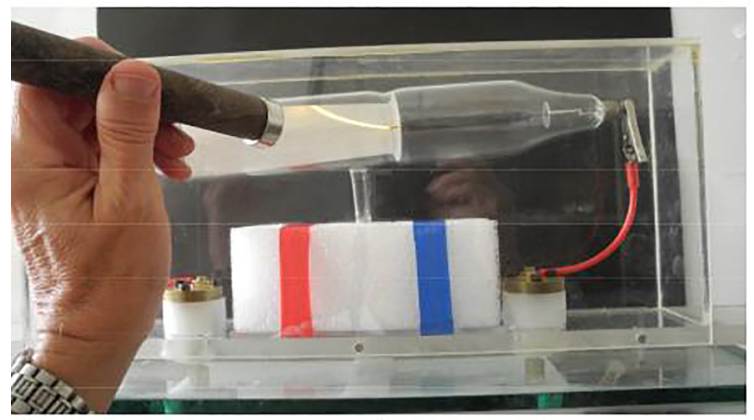

(b)

Figura 1: Partículas carregadas desviadas por um ímã. Fonte: http://www.ufjf.br/fisica/files/2013/10/FIII06-01-0-campo-magn\%C3\%A9tico.pdf. 
éter. As pesquisas de Thomson indicaram que longe de serem algum efeito desconhecido, os raios tratavam-se, na verdade de partículas, com razão carga-massa bem determinada, conduzindo-o a ganhar o Nobel pela descoberta do elétron.

Os fatos experimentais observados são os seguintes:

$i$. A força magnética, que chamaremos $\vec{F}_{M}$ sentida pelas partículas carregadas é perpendicular à velocidade $\vec{v}$ do feixe. A visualização da Figura 1 claramente mostra isso.

ii. Controlando a diferença de potencial entre as placas, podemos mudar a velocidade, de modo que a força depende linearmente da velocidade.

Apesar de nossa experiência não revelar, mas é possível verificar também que a força é proporcional à carga $q$ das partículas do feixe. Para isso, poderíamos tentar gerar feixes com cargas distintas. A força também depende linearmente de $q$. Reunindo os fatos acima, escrevemos, seguindo [1],

$$
\vec{F}_{M}=q \mathcal{M}(\vec{v})
$$

onde $\mathcal{M}$ é um operador linear que leva um vetor velocidade em um vetor força ${ }^{1}$

$$
\begin{aligned}
\mathcal{M}: \mathbb{V} & \rightarrow \mathbb{F} \\
\vec{v} & \mapsto \vec{F} .
\end{aligned}
$$

Escolhemos a letra $\mathcal{M}$ por ser a inicial de magnetismo. Vamos agora obter a estrutura geral desse objeto.

Vetores são objetos geométricos, cuja construção operacional pode ser vista em 13. Contudo, por praticidade, é costume definir um espaço universal $\mathbb{U}$ que admite uma base ortonormal de vetores $\mathcal{B}=\left\{\hat{e}_{i}\right\}$, com $i=1,2,3$ e a partir daí gera-se qualquer espaço vetorial de grandezas físicas fazendo combinações lineares dos vetores de $\mathcal{B}$ com os devidos escalares, gerando espaços de força, velocidade, etc. Fixada então uma determinada base, podemos representar unicamente vetores por colunas. Assim, dado, digamos $\vec{F} \in \mathbb{F}$, escrevemos

$$
[\vec{F}]_{\mathcal{B}}=\left(\begin{array}{l}
F_{1} \\
F_{2} \\
F_{3}
\end{array}\right)
$$

para representar $\vec{F}$ na base $\mathcal{B}$. Os escalares $F_{i}, i=1,2,3$ são as componentes do vetor $\vec{F}$ na respectiva base. $\mathrm{O}$ mesmo vale para $\mathcal{M}$ : sendo um operador linear que tem espaços de saída $(\mathbb{V})$ e de chegada $(\mathbb{F})$ tridimensionais, então $\mathcal{M}$ pode ser representado na base $\mathcal{B}$ por uma $3 \times 3$ matriz, com componentes $M_{i j}$. Assim, (2) pode ser escrita na base $\mathcal{B}$ como

$$
F_{i}=q \sum_{j=1}^{3} M_{i j} v_{j} \Leftrightarrow\left(\begin{array}{l}
F_{1} \\
F_{2} \\
F_{3}
\end{array}\right)=q\left(\begin{array}{lll}
M_{11} & M_{12} & M_{13} \\
M_{21} & M_{22} & M_{23} \\
M_{31} & M_{32} & M_{33}
\end{array}\right)\left(\begin{array}{l}
v_{1} \\
v_{2} \\
v_{3}
\end{array}\right) .
$$

\footnotetext{
$\overline{{ }^{1} \text { Neste caso, dizemos que } \mathcal{M}}$ é um tensor do tipo $(1,1)$. Os detalhes para construção de tensores podem ser vistos em 13.
}

Ressaltamos que cada entrada $F_{i}$ da expressão acima tem unidade de força, ou seja, $\mathrm{N}$ no S.I. Logo, os representantes $M_{i j}$ de $\mathcal{M}$ possuem, por sua vez, unidades $\left[M_{i j}\right]=N s / m C$, deixando a expressão 4 dimensionalmente correta.

Vamos agora fixar algumas direções específicas para a velocidade, de forma que seja possível estimar para onde aponta $\vec{F}$ e com isso, ganhamos informação sobre os $M_{i j}$. Começamos com o seguinte setup inicial. Suponhamos que um feixe de partículas carregadas tenha velocidade dada por $\vec{v}=v_{1} \hat{e}_{1}$. Como $\vec{F}_{M}$ é ortogonal à velocidade, a componente 1 de $\vec{F}$ é nula, isto é, $\vec{F}=F_{2} \hat{e}_{2}+F_{3} \hat{e}_{3}$. Neste caso, a partir de (4),

$$
F_{1}=0=M_{11} v_{1}+M_{12} 0+M_{13} 0 \Rightarrow M_{11}=0 .
$$

Analogamente, tomando agora velocidades do feixe incidente nas direções 2 e 3 , podemos concluir que $M_{22}=$ $M_{33}=0$. Isto é, a representação de $\mathcal{M}$ na base $\mathcal{B}$ é feita por uma matriz com diagonal nula.

Fixamos, por sua vez, um feixe com velocidade na direção

$$
\vec{v}=v \hat{i}+v \hat{j}=v(\hat{i}+\hat{j}) .
$$

Como $\vec{F} \perp \vec{v}$, temos $\vec{F} \cdot \vec{v}=0$. Assim

$$
\begin{aligned}
0 & =[q \mathcal{M}(\vec{v})] \cdot \vec{v} \\
& =q\left[\left(\begin{array}{ccc}
0 & M_{12} & M_{13} \\
M_{21} & 0 & M_{23} \\
M_{31} & M_{32} & 0
\end{array}\right)\left(\begin{array}{l}
v \\
v \\
0
\end{array}\right)\right] \cdot\left(\begin{array}{l}
v \\
v \\
0
\end{array}\right) \\
& =q\left(\begin{array}{c}
v M_{12} \\
v M_{21} \\
v\left(M_{31}+M_{32}\right)
\end{array}\right) \cdot\left(\begin{array}{l}
v \\
v \\
0
\end{array}\right) \Rightarrow M_{12}+M_{21}=0 .
\end{aligned}
$$

Considerações análogas nos permitem concluir que $M_{13}+M_{31}=0$ e $M_{23}+M_{32}=0$. É interessante notar que os fatores $q$ e $v$ podem ser colocados em evidência e não interferem nos cálculos na implicação obtida acima, no fim de (7). Com isso, concluímos que $\mathcal{M}$ deve ser representado por uma $3 \times 3$-matriz antissimétrica, que só possui 3 graus de liberdade. Redefinindo as entradas de $[\mathcal{M}]_{\mathcal{B}}$ como $M_{12} \equiv B_{3}, M_{13} \equiv-B_{2}$ e $M_{23} \equiv B_{1}$, teremos

$$
\begin{aligned}
\left(\begin{array}{l}
F_{1} \\
F_{2} \\
F_{3}
\end{array}\right)= & q\left(\begin{array}{ccc}
0 & B_{3} & -B_{2} \\
-B_{3} & 0 & B_{1} \\
B_{2} & -B_{1} & 0
\end{array}\right)\left(\begin{array}{l}
v_{1} \\
v_{2} \\
v_{3}
\end{array}\right) \\
= & q\left(\begin{array}{c}
v_{2} B_{3}-v_{3} B_{2} \\
-v_{1} B_{3}+v_{3} B_{1} \\
v_{1} B_{2}-v_{2} B_{1}
\end{array}\right) .
\end{aligned}
$$

A expressão acima pode ser escrita de maneira compacta por

$$
\vec{F}=q \vec{v} \times \vec{B} .
$$

Pontuamos que as entradas $M_{i j}$ e $B_{k}$ possuem as mesmas unidades, por construção. Ou seja, (4) e (9) são equivalentes e consistentes dimensionalmente. Além disso, note que a notação acima de produto vetorial, até agora é sim- 
plesmente um arranjo formal para descrever a atuação de $\mathcal{M}$ sobre $\vec{v}$. Como podemos ter certeza que o ímã que atua sobre o fluxo de partículas tem, de fato, um caráter vetorial? Afinal, até agora as entradas $B_{1}, B_{2}$ e $B_{3}$ não podem ser chamadas de componentes de um vetor na base $\mathcal{B}$.

Uma das maneiras de se caracterizar um vetor consiste em ver seu comportamento sob uma rotação, que nada mais é que uma transformação linear. Sendo $\mathcal{R}$ o operador que representa uma rotação, temos

$$
\vec{F} \stackrel{\mathcal{R}}{\mapsto} \vec{F}^{\prime}=\mathcal{R} \vec{F} \text { e } \vec{v} \stackrel{\mathcal{R}}{\mapsto} \vec{v}^{\prime}=\mathcal{R} \vec{v},
$$

onde $\vec{F}^{\prime}$ e $\vec{v}^{\prime}$ correspondem aos vetores força e velocidade que sofreram a rotação. Podemos usar este fato para extrair qual a regra de transformação para $\mathcal{M}$ sob uma rotação. Apelando para o princípio da relatividade [4], deve valer a seguinte equivalência

$$
\vec{F}=q \mathcal{M}(\vec{v}) \Leftrightarrow \vec{F}^{\prime}=q \mathcal{M}^{\prime}\left(\vec{v}^{\prime}\right),
$$

afinal, as leis da física devem ser as mesmas para qualquer referencial. Usando as transformações de $\vec{F}$ e $\vec{v}$ dadas em (10) na segunda parte de (11), temos

$$
\mathcal{R} \vec{F}=q \mathcal{M}^{\prime}(\mathcal{R} \vec{v}) \Leftrightarrow \vec{F}=q\left(\mathcal{R}^{-1} \mathcal{M}^{\prime} \mathcal{R}\right)(\vec{v}) .
$$

Para que valha a equivalência 11 exigida pelo princípio da relatividade, devemos ter

$$
\mathcal{M}=\mathcal{R}^{-1} \mathcal{M}^{\prime} \mathcal{R} \Leftrightarrow \mathcal{M}^{\prime}=\mathcal{R} \mathcal{M} \mathcal{R}^{-1}
$$

Ganhamos então a regra de transformação para $\mathcal{M}$ sob uma rotação. Resta agora ver o que (13) impõe sobre $\vec{B}$, que ainda não sabemos como se transforma sob uma rotação. Um cálculo direto mostra que

$$
\vec{B} \rightarrow \vec{B}^{\prime}=\mathcal{R} \vec{B}
$$

De fato, fixe uma rotação ao redor do eixo $z$ por um ângulo $\theta$, representada por

$$
\mathcal{R}_{z}(\theta)=\left(\begin{array}{ccc}
\cos \theta & \operatorname{sen} \theta & 0 \\
-\operatorname{sen} \theta & \cos \theta & 0 \\
0 & 0 & 1
\end{array}\right)
$$

Temos então, a partir de 13

$$
\mathcal{M}^{\prime}=\left(\begin{array}{ccc}
0 & B_{3} & \mathrm{M}_{12} \\
-B_{3} & 0 & \mathrm{M}_{21} \\
-\mathrm{M}_{12} & -\mathrm{M}_{21} & 0
\end{array}\right)
$$

onde denotamos

$$
\mathrm{M}_{12} \equiv-B_{2} \cos \theta+B_{1} \operatorname{sen} \theta \text { e } \mathbb{M}_{12} \equiv B_{2} \operatorname{sen} \theta+B_{1} \cos \theta
$$

Em termos das entradas $B_{1}, B_{2}$ e $B_{3}$,

$$
\left(\begin{array}{l}
B_{1} \\
B_{2} \\
B_{3}
\end{array}\right) \rightarrow\left(\begin{array}{l}
B_{1}^{\prime} \\
B_{2}^{\prime} \\
B_{3}^{\prime}
\end{array}\right)=\left(\begin{array}{ccc}
\cos \theta & \operatorname{sen} \theta & 0 \\
-\operatorname{sen} \theta & \cos \theta & 0 \\
0 & 0 & 1
\end{array}\right)\left(\begin{array}{l}
B_{1} \\
B_{2} \\
B_{3}
\end{array}\right) .
$$

Ora, esses cálculos mostram exatamente que $\vec{B}$ se comporta como um vetor sob uma rotação. Somente agora temos o direito de chamá-lo de um vetor. O mesmo vale para rotações ao redor dos eixos $x$ e $y$. A expressão (13) de transformação de $\mathcal{M}$ sob uma rotação o caracteriza como um tensor 13 e nada mais é que uma generalização natural para 10. Com efeito, em termos de componentes, um vetor $\vec{F}$, com entradas $F^{i}, i=1,2,3$ em certa base $\mathcal{B}$, se transforma sob uma rotação como

$$
F^{i} \rightarrow F^{i}=\mathcal{R}_{j}^{i} F^{j}
$$

Como $\mathcal{R}$ é uma matriz de rotação, temos 4],

$$
\mathcal{R}^{T}=\mathcal{R}^{-1} \Leftrightarrow\left(\mathcal{R}^{T}\right)^{i}{ }_{j}=\left(\mathcal{R}^{-1}\right)^{i}{ }_{j}
$$

Assim, em termos de componentes, (13) ganha a forma

$$
\begin{aligned}
{\left[\mathcal{M}^{\prime}\right]_{j}^{i} } & =\mathcal{R}^{i}{ }_{k}[\mathcal{M}]^{k}{ }_{l}\left(\mathcal{R}^{-1}\right)^{l}{ }_{j} \\
& =\mathcal{R}^{i}{ }_{k}\left(\mathcal{R}^{T}\right)^{l}{ }_{j}[\mathcal{M}]^{k}{ }_{l} \\
& =\mathcal{R}^{i}{ }_{k} \mathcal{R}_{j}{ }^{l}[\mathcal{M}]^{k}{ }_{l},
\end{aligned}
$$

que nada mais é do que a caracterização de um tensor via sua lei de transformação sob uma rotação da base em que ele é representado. Nossos cálculos mostram um resultado geral: uma grandeza representada por uma $3 \times 3$-matriz antissimétrica que atua sobre vetores pode ser reduzida a um produto vetorial:

$$
\mathcal{M}(\vec{v}) \Leftrightarrow \vec{v} \times \vec{B}
$$

Até agora vimos que o campo magnético se comporta como um vetor quando rotacionado. O que ocorre quando refletimos $\vec{B}$ ? Um vetor, com a representação geométrica usual de uma seta, tem o comportamento bem definido quando é refletido. Sua imagem troca de sentido quando ele é colocado perpendicular ao plano do espelho e a imagem não é alterada quando o vetor está paralelo ao plano do espelho, conforme indica o par (a) e (b) na Figura 2

Vejamos agora o comportamento de $\vec{B}$ sob uma reflexão. Consideremos uma partícula de carga $q$ e com velocidade $\vec{v}$, atravessando uma região espacial com campo magnético $\vec{B}$. A partícula sente uma força $\vec{F}$. Vamos analisar a reflexão de $\vec{v}, \vec{F}$ e $\vec{B}$ desta situação. Podemos colocar um espelho perpendicular a $\vec{v}$ e paralelo a $\vec{F}$. Neste caso, as imagens são dadas por $\vec{v}^{\prime}=-\vec{v}$ e $\vec{F}^{\prime}=\vec{F}$, uma vez que $\vec{v}$ e $\vec{F}$ são vetores. Como $q$ não deve ser alterada sob uma reflexão e, ainda, $\vec{F}^{\prime}=q \vec{v}^{\prime} \times \vec{B}^{\prime}$, nossa única opção é que $\vec{B}^{\prime}=-\vec{B}$, conforme indica a Figura 3

Uma consideração análoga quando $\vec{B}$ está perpendicular ao plano do espelho nos leva a $\vec{B}^{\prime}=\vec{B}$. Ou seja, 
o campo magnético tem o comportamento oposto de um vetor quando refletido. Assim, o chamamos de um pseudo-vetor ou vetor axial. Convidamos o(a) leitor(a) a propor um experimento de reflexão para um corpo em rotação. O que ocorre com a velocidade angular $\vec{\omega}$ neste caso?

Um outro problema que por vezes é deixado de lado sobre campos magnéticos, e talvez seja o mais atrativo de todos é a determinação da força de atração ou repulsão entre ímãs: pessoas com as mais diferentes idades ficam maravilhadas quando brincam com ímãs e descobrem estes efeitos. Os livros de eletromagnetismo básico mostram como estimamos o valor de $\vec{B}$, seja por Biot-Savart ou seja pela de Ampère em distribuições de correntes com certa simetria e são também indicados os cálculos de forças sobre partículas carregadas. Contudo, a descrição quantitativa do efeito de interação, por exemplo, entre a agulha de uma bússola e o campo magnético terrestre é deixada de lado. Não é por menos. Tal tarefa, até pouco tempo atrás, só era feita de forma numérica. Na próxima

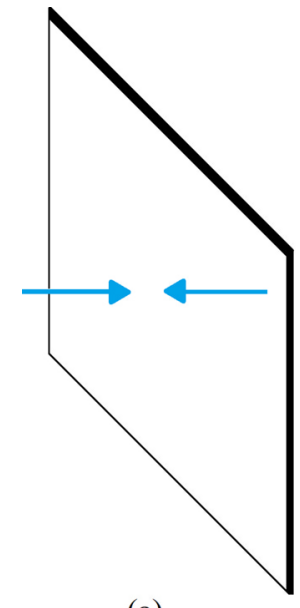

(a)

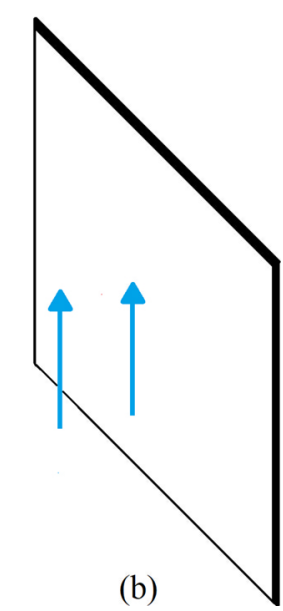

(b)
Figura 2: Comportamento de vetores por reflexões.

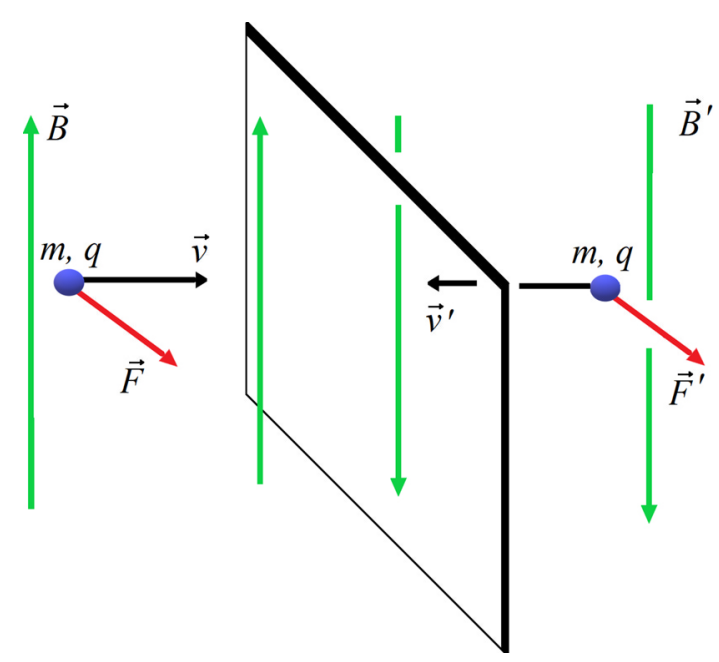

Figura 3: Comportamento do campo magnético sob uma reflexão.
Seção discutiremos as razões pelas quais determinar a força de interação entre dois ímãs pode se tornar tão complexa, que acaba fugindo do escopo da física básica. Vamos sugerir, contudo, uma saída para a descrição analítica do campo de forças entre ímãs cilíndricos, com base em trabalhos recentes.

\section{Modelando a Interação entre Ímãs}

Passemos agora a discutir como calcular a força entre dois magnetos. Faremos indicações da literatura correspondente em alguns momentos, já que o assunto acaba se tornando avançado, fugindo dos propósitos deste artigo.

Uma proposta inicial para estimar a força seria utilizar a interação entre campo magnético e correntes. Dados dois ímãs 1 e 2 com campos $\vec{B}_{1}$ e $\vec{B}_{2}$, poderíamos estimar quais são as densidades de corrente volumétrica e superficial $\vec{J}_{2}=\nabla \times \vec{M}_{2}$ e $\vec{K}_{2}=\vec{M}_{2} \times \hat{n}$ que geram $\vec{B}_{2}$ $\left(\vec{M}_{2}\right.$ corresponde à magnetização do ímã 2) no seguinte sentido: obtemos o vetor potencial

$$
\vec{A}_{2}(\vec{r}):=\frac{\mu_{0}}{4 \pi} \iiint_{(V)} \frac{\vec{J}_{2}\left(\vec{r}^{\prime}\right)}{\left|\vec{r}-\vec{r}^{\prime}\right|} d V^{\prime}+\frac{\mu_{0}}{4 \pi} \oiint_{(\partial V)} \frac{\vec{K}_{2}\left(\vec{r}^{\prime}\right)}{\left|\vec{r}-\vec{r}^{\prime}\right|} d S^{\prime}
$$

e então $\vec{B}_{2}=\nabla \times \vec{A}_{2}[2]$ ( $\left.V\right)$ corresponde ao volume que o ímã 2 ocupa e $(\partial V)$ à superfície fechada que delimita $(V)$. Daí estimamos a força que $\vec{B}_{1}$ faz sobre tais correntes.

A outra possibilidade mais recorrente na literatura é a utilização da (densidade de) força de Kelvin [14]. Já nos cursos de física básica [1], sabemos que um sistema formado por um dipolo magnético $\vec{m}$ imerso em um campo magnético $\vec{B}$ possui energia potencial magnética

$$
E_{P}=-\vec{m} \cdot \vec{B}
$$

Sendo a magnetização de determinado material, por definição, a densidade de dipolos,

$$
\vec{M}(\vec{r})=\frac{\sum_{i} \vec{m}_{i}}{\delta V}
$$

onde $\delta V$ corresponde a um volume infinitesimal do material, posicionado em $\vec{r}$, chegamos à densidade de energia potencial $e_{P}$,

$$
E_{P}=-\delta V \vec{M} \cdot \vec{B} \Rightarrow e_{P}:=\frac{E_{P}}{\delta V}=-\vec{M} \cdot \vec{B}
$$

Logo, a densidade de força $\vec{f}$ sobre o material magnetizado é, correspondentemente, dada por

$$
\vec{f}=-\nabla e_{P}=\nabla(\vec{M} \cdot \vec{B}) .
$$

Supondo então que $\vec{M}$ é a magnetização de um ímã imerso em uma região espacial permeada por um campo 
$\vec{B}$, a força total que o ímã sente é dada por

$$
\vec{F}=\iiint_{(V)} \nabla(\vec{M} \cdot \vec{B}) d V
$$

$(V)$ corresponde ao volume delimitado pelo ímã.

Como nosso intuito é descrever a força entre ímãs, nitidamente, por (26), precisamos conhecer tanto a magnetização de um deles quanto o campo gerado pelo outro. Mais ainda, (26) é sensível quanto à geometria dos ímãs, que interferem na forma dos campos $\vec{M}$ e $\vec{B}$.

Curiosamente, tanto estimativas numéricas para (26) quanto a percepção de que ela admitia uma aproximação analítica são razoavelmente recentes, com trabalhos dos anos 2000 em diante $10,15,18$. Devido à sensibilidade da expressão (26) para com a geometria dos ímãs, os trabalhos focam a sua atenção para casos particulares, com ímãs cúbicos, cilíndricos, etc 10,19. Mais ainda, para a obtenção da força, é usual assumir que a magnetização de ambos os ímãs é constante 10. Como veremos à frente e de forma empírica, tal aproximação é razoável. Outro fator preponderante corresponde à orientação dos ímãs. Para ímãs cilíndricos (iguais) em particular, temos $\vec{M}=M_{0} \hat{k}$, com $M_{0}=$ constante e $\hat{k}$ é o vetor unitário que aponta na direção do eixo $z$. Tal eixo é posto sobre o eixo de simetria de rotação do cilindro. Com isso, o produto escalar em (26) fica reduzido a um termo: $\vec{M} \cdot \vec{B}=M_{0} B_{z}$. A determinação de $B_{z}$, por sua vez, é feita a partir da magnetização (veja (21)), e depende de integrais elípticas. Assim, ficamos restritos à utilização de métodos numéricos. Podemos apelar para a expansão das integrais elípticas em polinômios, séries de potência ou ainda, a série hipergeométrica, sendo esse o caminho adotado em 10: os autores fornecem uma expressão analítica para a força, veja (27). Não vamos deduzi-la aqui. Existem, contudo, algumas razões principais que nos levam a usar tal modelo, sendo adaptado para atividades experimentais, típicas de laboratórios de física básica. Vamos enumerá-las.

1) Os ímãs utilizados nos nossos experimentos possuem magnetização aproximadamente constante (mesmo um estando na presença do outro). Com isso, satisfazemos uma das exigências requeridas em [10], de onde tiramos a expressão analítica para a força entre os ímãs. Para comprovar este fato, considere as linhas de campo dos ímãs feitas com limalha de ferro, expostas na Figura 4

Em (a), temos o ímã 01, em (b) o ímã 2 e (c) mostra o delineamento das linhas exatamente sobre o ímã. As características dos magnetos podem ser vistas na Tabela 1 . Temos um campo magnético similar a um solenoide com tamanho finito. Além disso, na região espacial delimitada pelo ímã, temos linhas indicando magnetização uniforme. Tais linhas sugerem que a distribuição de corrente volumétrica é nula, pois $\vec{J}=\nabla \times \vec{M}$ e a superficial é dada por $\vec{K}=\vec{M} \times \hat{n}$, sendo o $\hat{n}$ o vetor unitário normal à superfície do ímã. A Figura 5 fornece uma representação geométrica dos vetores $\vec{K}$, $\hat{n}$, a magnetização constante

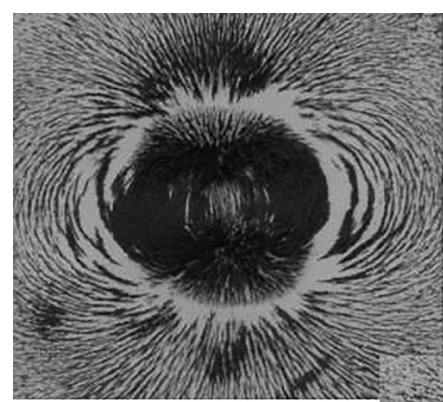

(a)

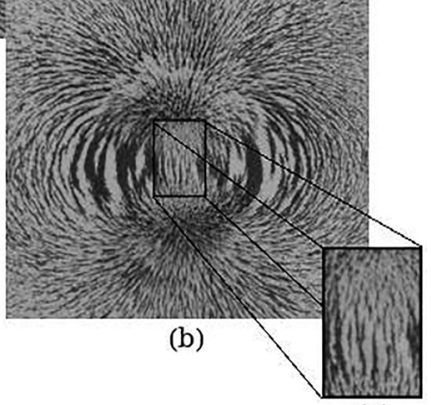

(c)

Figura 4: Linhas de campo dos ímãs utilizados nos experimentos em (a) e (b). Em (c) tem-se uma visão ampliada das linhas de campo exatamente sobre o ímã.

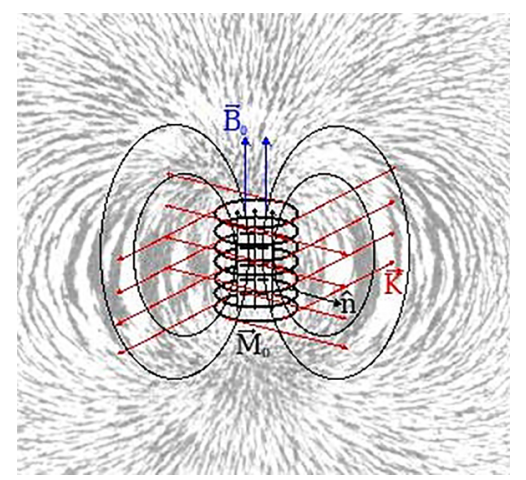

Figura 5: Superposição de um solenoide com as linhas de campo de um dos ímãs utilizados neste trabalho.

$\vec{M}_{0}$ no interior de um solenoide imaginário e $\vec{B}_{0}=\mu_{0} \vec{M}_{0}$ em um dos polos. O solenoide foi propositalmente superposto às linhas de campo de um dos ímãs utilizados neste trabalho.

2) O último argumento a favor de utilizarmos o modelo teórico de [10], com uma proposta de atividade baseada nos experimentos de [19], está ligada com a sua representação gráfica. A expressão (25) de 10 fornece o módulo da força entre dois ímãs iguais como função da distância $d$ entre as superfícies, chamada de gap axial. Ela é dada por

$$
\begin{aligned}
& \frac{F(d)}{\eta_{0}}=\frac{a^{2}}{4}\left(\frac{A B-d C}{B C}\right)+\frac{3 a^{6}}{32}\left[\frac{A B^{5}-d C^{5}}{B^{5} C^{5}}\right]+ \\
& +\frac{5 a^{8}}{256}\left[\frac{A\left(3 a^{2}-4 A^{2}\right) B^{9}+d\left(4 d^{2}-3 a^{2}\right) C^{9}}{B^{9} C^{9}}\right],
\end{aligned}
$$

onde, para simplificar a expressão, definimos, 
Tabela 1: Materiais utilizados nas atividades experimentais.

\begin{tabular}{|c|c|c|c|c|}
\hline Ord. & Materiais & Especificações & Qtd. & Unid. \\
\hline 01 & Ímã de neodímio & $\begin{array}{l}\text { Neodímio-Ferro-Boro NdFeB, grade magnética-N35, formato cilíndrico com } 20 \times \\
6 \mathrm{~mm} \text {, campo no polo: } 0,3115 T\end{array}$ & 02 & Unid. \\
\hline 02 & Ímã de neodímio & $\begin{array}{l}\text { Neodímio-Ferro-Boro NdFeB, grade magnética-N35, formato cilíndrico com } 12,7 \times \\
6,35 \mathrm{~mm} \text {, campo no polo } 0,428 T\end{array}$ & 02 & Unid. \\
\hline 03 & Trilho de ar & Marca Phywe, comprimento $2 \mathrm{~m}$. & 01 & Unid. \\
\hline 04 & Compressor & Compressor de ar com mangueira e 5 níveis & 01 & Unid. \\
\hline 05 & Carrinho & Carrinho em alumínio para o trilho de ar & 01 & Unid. \\
\hline 06 & Terminal do trilho de ar & Terminal em polipropileno & 01 & Unid. \\
\hline 07 & Régua & Régua milimetrada, $20 \mathrm{~cm}$, plástico & 01 & Unid. \\
\hline 08 & Sensor de força & $\begin{array}{l}\text { Marca Pasco, modelo PS3202, Ranger } \pm 50 \mathrm{~N} \text {, Acurácia de } 0,1 \mathrm{~N} \text { e } 0,03 \mathrm{~N} \text { de } \\
\text { resolução }\end{array}$ & 01 & Unid. \\
\hline 09 & Porta peso & Porta peso de massa $10 \mathrm{~g}$ & 01 & Unid. \\
\hline 10 & Linha & Linha de costura & 1,5 & $\mathrm{~m}$ \\
\hline 11 & Pesos & Pesos de massa com $10 \mathrm{~g}$, aproximadamente & 20 & Unid. \\
\hline 12 & Suporte & Suporte para roldana & 01 & Unid. \\
\hline 13 & Roldana & Roldana de baixo atrito, marca Phywe & 01 & Unid. \\
\hline 14 & Mola & Mola com constante elástica $18,58 \mathrm{~N} / \mathrm{m}$ & 01 & Unid. \\
\hline 16 & Braçadeira & Em material de alumínio & 01 & Unid. \\
\hline 17 & Suporte para braçadeira & Em material de alumínio & 01 & Unid. \\
\hline 18 & Garra & Em material de alumínio & 01 & Unid. \\
\hline 19 & Suporte para garra & Em material de alumínio & 01 & Unid. \\
\hline 20 & Régua milimetrada & Em madeira com $1 \mathrm{~m}$ de comprimento e dois marcadores deslizáveis de plástico. & 01 & Unid. \\
\hline 21 & Suporte & Suporte de ferro para régua & 01 & Unid. \\
\hline
\end{tabular}

$\eta_{0}:=2 \pi \mu_{0} M_{0}^{2}, A:=4 t+d, B:=\left(d^{2}+a^{2}\right)^{\frac{1}{2}}$ e $C:=$ $\left[(4 t+d)^{2}+a^{2}\right]^{\frac{1}{2}}$.

$2 a$ e $2 t$ são, respectivamente, diâmetro e altura dos ímãs. Como não é o intuito deste trabalho, não vamos demonstrar esta expressão. Nosso foco, é na verdade, mostrar que ela admite uma representação gráfica aproximada por uma exponencial da forma

$$
F(d)=\sigma+\alpha_{i} e^{\beta_{i} d}
$$

na região de interação entre os ímãs. De fato, o gráfico da Figura 6 mostra a plotagem de (27) para um dos pares de ímãs (ímã 2 da Tabela 1) utilizados (em vermelho) e a curva em azul corresponde à curva $F(d)=0.06+$ $4,27 e^{-0,15 d}$. Apesar de não ser a resposta exata, podemos afirmar, com este resultado, que a força entre dois ímãs cilíndricos iguais, alinhados sobre o eixo de simetria de ambos, decai com a exponencial em (28), com $\sigma \approx 0$. Utilizamos no eixo das distâncias valores que vão de $9 \mathrm{~mm}$ a $34 \mathrm{~mm}$, que corresponde ao intervalo de medidas do experimento (veja Tabela 2).

Tal resultado naturalmente não é adequado, digamos para aplicações tecnológicas, que demandam ajuste fino. Por outro lado, utilizá-lo em sala de aula ou atividades de laboratório, já fornece, com boa aproximação, o comportamento da força entre ímãs.

Por fim, destacamos que as atividades experimentais que propomos, além de serem de simples reprodução, são exatamente aquelas cujo arcabouço teórico é dado nas referências acima listadas. Além disso, temos a chance de estimar valores para o efeito de interação entre ímãs, além de verificarmos experimentalmente a validade das estimativas.

\section{Materiais e Métodos}

Após toda a discussão sobre a determinação da força entre ímãs apresentada anteriormente, detalharemos agora uma sequência de experimentos cujos dados coletados permitem determinar um modelo efetivo de interação entre ímãs cilíndricos iguais. Utilizamos pares de ímãs permanentes de NdFeB e materiais descritos na Tabela 1. Montamos três configurações distintas, que serão detalhadas ao longo da Seção.

\subsection{Procedimento metodológico}

A pesquisa foi realizada a $26^{\circ} \mathrm{C}$, no Laboratório de Física I do Instituto de Educação Agricultura e Ambiente da

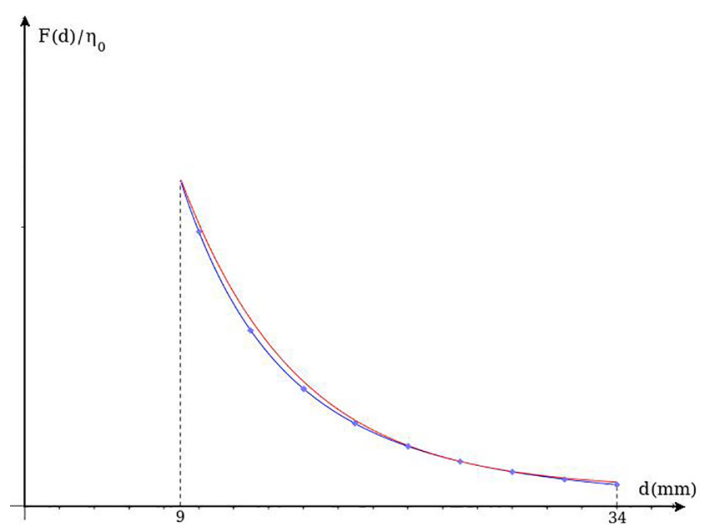

Figura 6: Plotagem da força por distância para dois ímãs idênticos cilíndricos por distância, em azul. A curva vermelha é a aproximação por uma exponencial. 
Tabela 2: Valores observados nas três atividades experimentais.

\begin{tabular}{cc|cc|cc}
\hline \multicolumn{2}{c}{ Atividade 1} & \multicolumn{2}{c}{ Atividade 2} & \multicolumn{2}{c}{ Atividade 3} \\
\hline$d(\mathrm{~m})$ & $F_{P}(\mathrm{~N})$ & $d(\mathrm{~m})$ & $F_{E}(\mathrm{~N})$ & $d(\mathrm{~m})$ & $F_{x}(\mathrm{~N})$ \\
\hline 0,0345 & 0,10 & 0,0380 & 0,065 & 0,0345 & 0,095 \\
0,0275 & 0,19 & 0,0325 & 0,111 & 0,0310 & 0,127 \\
0,0240 & 0,29 & 0,0300 & 0,130 & 0,0285 & 0,159 \\
0,0215 & 0,38 & 0,0280 & 0,186 & 0,0275 & 0,190 \\
0,0200 & 0,48 & 0,0265 & 0,204 & 0,0265 & 0,222 \\
0,0190 & 0,57 & 0,0255 & 0,242 & 0,0250 & 0,253 \\
0,0180 & 0,67 & 0,0250 & 0,297 & 0,0240 & 0,285 \\
0,0170 & 0,76 & 0,0230 & 0,353 & 0,0230 & 0,316 \\
0,0160 & 0,85 & 0,0215 & 0,390 & 0,0220 & 0,347 \\
0,0150 & 0,95 & 0,0205 & 0,446 & 0,0215 & 0,378 \\
0,0145 & 1,05 & 0,0190 & 0,511 & 0,0210 & 0,409 \\
0,0140 & 1,15 & 0,0180 & 0,576 & 0,0200 & 0,471 \\
0,0135 & 1,24 & 0,0175 & 0,669 & 0,0195 & 0,532 \\
0,0130 & 1,34 & 0,0165 & 0,790 & 0,0180 & 0,622 \\
0,0125 & 1,44 & 0,0150 & 0,966 & 0,0170 & 0,711 \\
0,0120 & 1,63 & 0,0140 & 1,078 & 0,0165 & 0,798 \\
0,0115 & 1,72 & 0,0130 & 1,282 & 0,0160 & 0,882 \\
0,0110 & 1,92 & 0,0120 & 1,486 & 0,0150 & 0,991 \\
0,0105 & 2,11 & 0,0110 & 1,635 & 0,0145 & 1,070 \\
0,0100 & 2,20 & $\ldots$ & $\ldots$ & $\ldots$ & $\ldots$ \\
\hline
\end{tabular}

Universidade Federal do Amazonas em Humaitá - AM $\left(07^{\circ} 30^{\prime} 22^{\prime \prime} \mathrm{S}, 63^{\circ} 01^{\prime} 15\right.$ ” W).

Propomos três experimentos que justificam-se pelas montagens relativamente simples e mesma metodologia para coleta de dados, embora apresentem configurações diferentes. Os ímãs iguais são afastados, com eixos de simetria coincidentes e coletamos a força de repulsão entre os mesmos, medindo também cada gap axial correspondente. As forças magnéticas foram obtidas utilizando três setups distintos, ambos realizados no trilho de ar, com o compressor ligado no nível 2.

No primeiro, estabelecemos o equilíbrio estático quando os ímãs são aproximados em uma adaptação de uma máquina de Atwood. A força magnética pode ser determinada medindo o peso de um conjunto de massas presas a um dos ímãs, que os aproxima. Na segunda, os ímãs são aproximados, sendo que um deles é preso a um sistema massa-mola. No equilíbrio, a força elástica se equilibra à força magnética, permitindo estimar a última. Por fim, utilizamos um plano inclinado. Os ímãs são agora aproximados a partir de diferentes inclinações do plano. Novamente, no equilíbrio igualamos uma componente de força peso com a força magnética de interesse.

Para cada setup, um ímã era posicionado em uma extremidade do trilho e outro numa face do carrinho (Figura 7). As subseções a seguir detalham os experimentos, com ilustrações das montagens utilizando um par de ímãs de neodímio com $12,7 \mathrm{~mm}$ de diâmetro e $6,35 \mathrm{~mm}$ de altura. O mesmos experimentos foram aplicados para o par de ímãs de neodímio de $20 \mathrm{~mm}$ de diâmetro por $6 \mathrm{~mm}$ de altura. Além disso, para cada uma delas, os detalhes de coleta de dados são oferecidos, com minúcias particulares de cada uma das configurações.

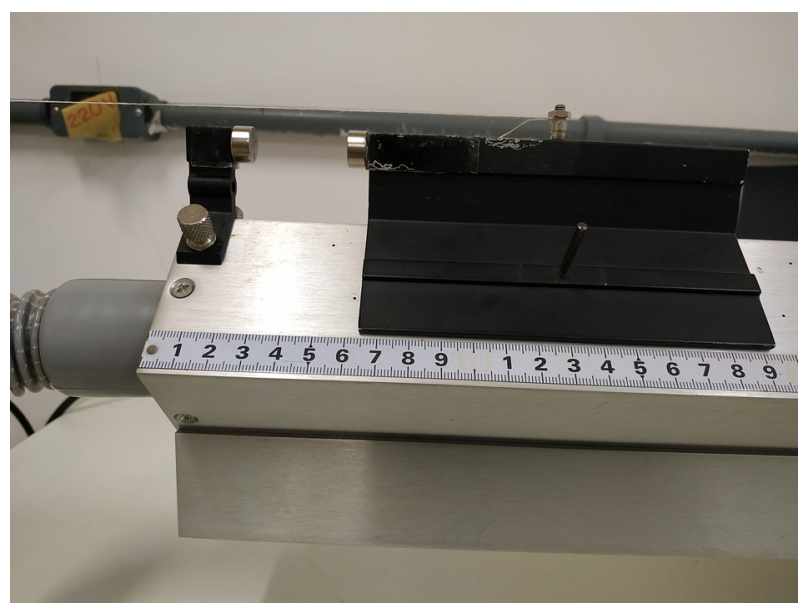

Figura 7: Posicionamento para cada par de ímãs de neodímio em todas as atividades realizadas.

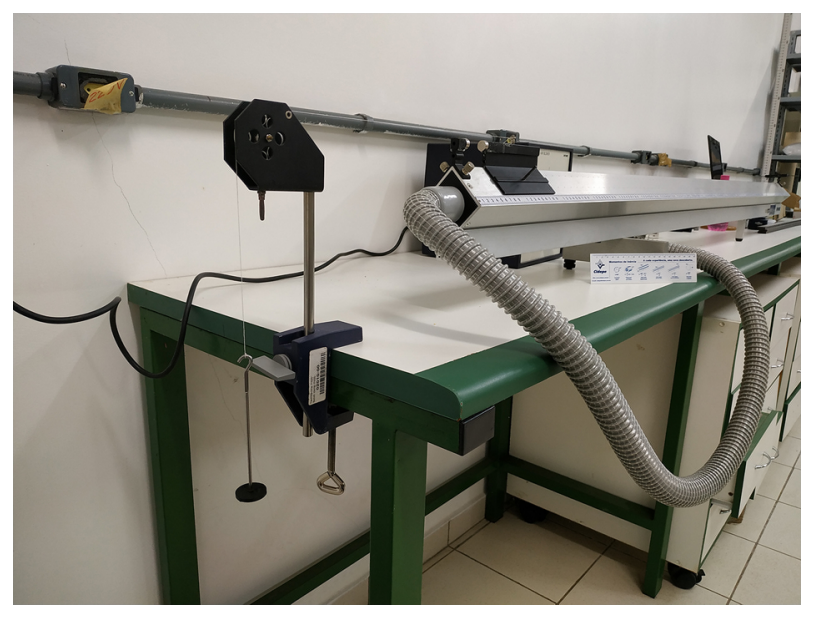

Figura 8: Montagem experimental para realização da primeira atividade.

\subsection{Atividade 1: força peso versus força magnética}

Para a primeira atividade colocamos uma roldana com atrito desprezível atrás da extremidade do trilho com o ímã, esta roldana foi alinhada com o carrinho e o terminal do trilho. Em seguida foi amarrado uma linha no carrinho, linha esta que passava pela roldana e continha um porta peso amarrado em sua outra extremidade como mostrado na Figura 8

Iniciamos a atividade com o porta peso munido apenas de sua massa inicial, para medirmos, com uma régua milimetrada, a distância inicial entre os ímãs (Figura 9. a). Em seguida, variamos a força peso acrescendo massa ao porta peso e, novamente, medimos a distância entre os ímãs. Este processo foi repetido até o preenchimento da capacidade máxima do porta peso (Figura 9-b).

Considerando o sistema em equilíbrio estático, segue que o arranjo de forças atuantes sobre o carrinho é tal que $\vec{F}_{T}+\vec{F}_{M}=\overrightarrow{0}$. Além disso, $\vec{F}_{T}^{\prime}+\vec{F}_{P}=\overrightarrow{0}$. Igualando os módulos das forças, chegamos a $\left|\vec{F}_{M}\right|=\left|\vec{F}_{P}\right|[20]$. Por 


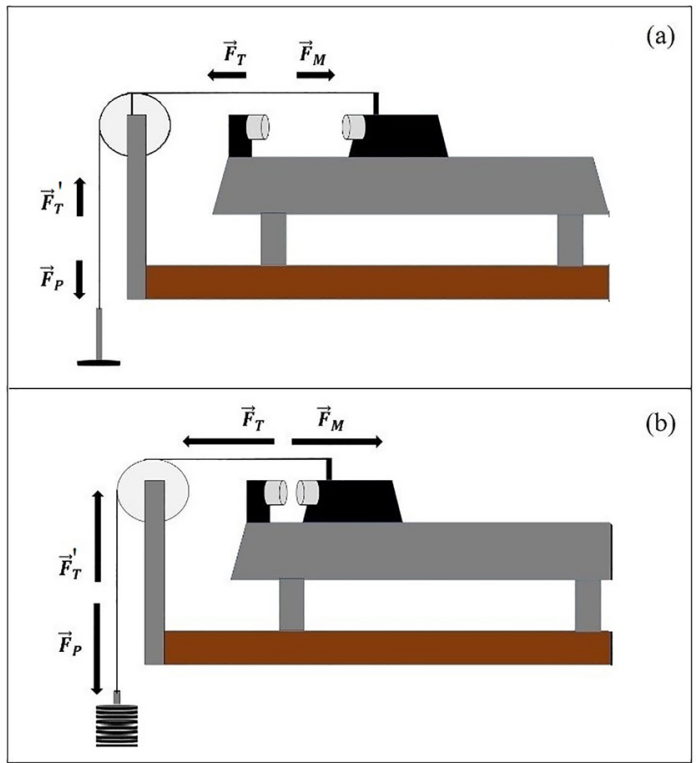

Figura 9: Esquema ilustrativo da primeira atividade.

$T, P$ e $M$ nas forças queremos dizer, respectivamente, tensão no fio, peso e força magnética. Nessa situação, consideramos o fio inextensível, com massa desprezível e uma polia ideal.

Encerrando a atividade, retiramos o porta peso com as massas nele contidas, sem perder a ordem em que foram adicionadas e, com o auxílio do sensor de força, medimos a força peso retirando massa por massa (Tabela 1).

Assim, esta atividade tem por objetivo relacionar a força magnética com a distância entre os ímãs, ou seja,

$$
\left|\vec{F}_{M}\right|=\left|\vec{F}_{P}\right| \propto|\vec{F}(d)| .
$$

\subsection{Atividade 2: força elástica versus força magnética}

Nesta atividade utilizamos uma mola, cuja constante elástica foi obtida por uma atividade extra, detalhada em 21. Uma vez determinada a constante da mola, prosseguimos com a atividade fixando a mola com uma guia interna na retaguarda do carrinho. E para comprimir a mola, utilizamos um suporte com uma braçadeira (Figura 10 .

Para iniciar a coleta de dados, primeiramente encontramos o "ponto de equilíbrio" 2 então medimos, com uma régua milimetrada, a distância entre os ímãs e o comprimento da mola (Figura 11 fa). Em seguida, arrastamos o suporte na direção do ímã fixado na extremidade do trilho e, novamente, as distâncias entre os ímãs e o comprimento da mola foram medidas. Repetimos este processo até saturar o poder de compressão da mola (Figura 11,b).

Neste caso, consideramos também o equilíbrio estático, ou seja, $\vec{F}_{E}+\vec{F}_{M}=\overrightarrow{0}$, implicando em $\left|\vec{F}_{E}\right|=\left|\vec{F}_{M}\right|$. Por $E$

${ }^{2}$ Distância limite entre os ímãs de modo que a interação não comprimisse a mola. e $M$ queremos dizer forças elástica e magnética. Desta forma, objetivamos com esta atividade obter a relação entre a força magnética e a distância entre os ímãs.

\subsection{Atividade 3: plano inclinado}

Iniciamos esta atividade fazendo uso do sensor de força com o qual medimos: (i) $1,82 \mathrm{~N}$ para força peso do carrinho, considerando o ímã menor fixado a ele e, (ii) $2,87 \mathrm{~N}$ para o carrinho com o ímã maior e com acréscimo de mais massa.

Em seguida, imprimimos ao sistema uma inclinação de $\theta_{0}=5^{\circ}$ em relação ao plano horizontal. Tal inclinação, serviu para determinarmos a distância inicial entre os ímãs onde a interação magnética pode ser detectada.

A partir do $\theta_{0}$, variamos a inclinação do trilho de ar de forma crescente até o limite máximo de medida da régua milimetrada (Figura 12 .

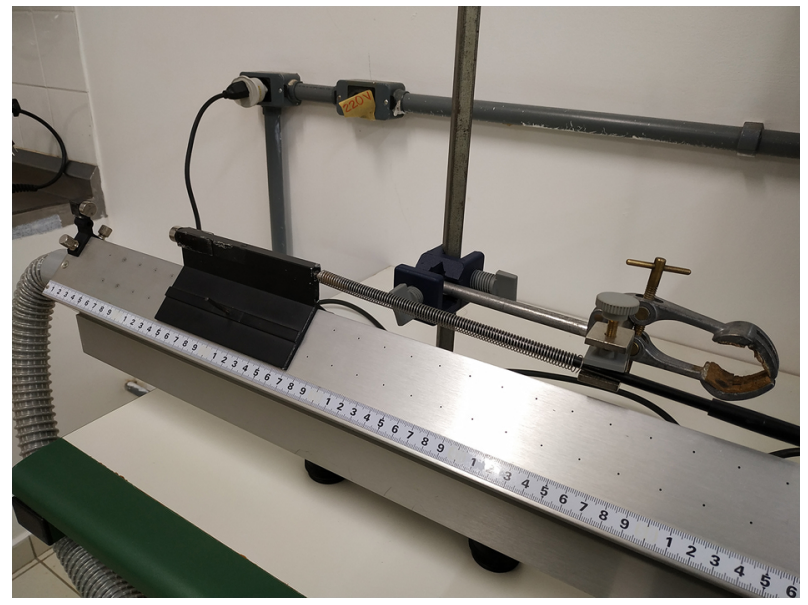

Figura 10: Montagem experimental para realização da segunda atividade.

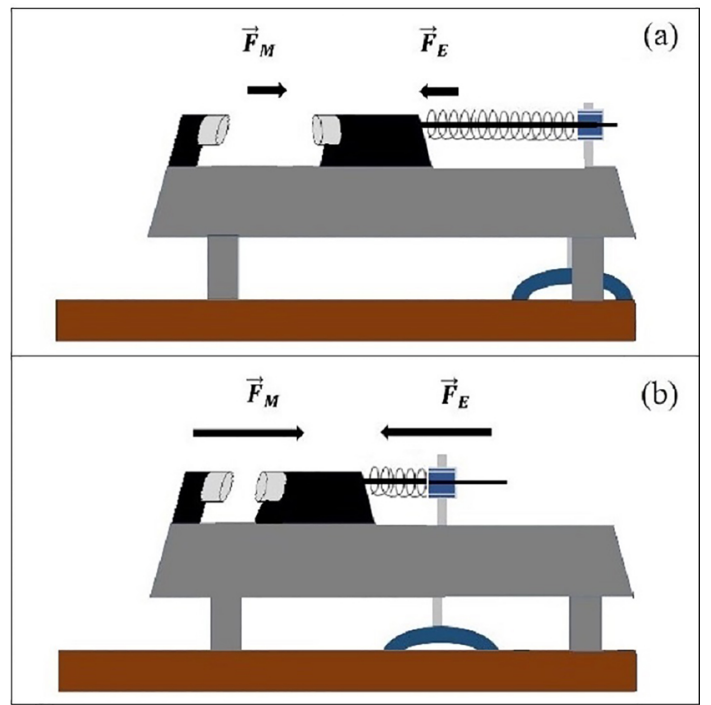

Figura 11: Esquema ilustrativo da segunda atividade. 


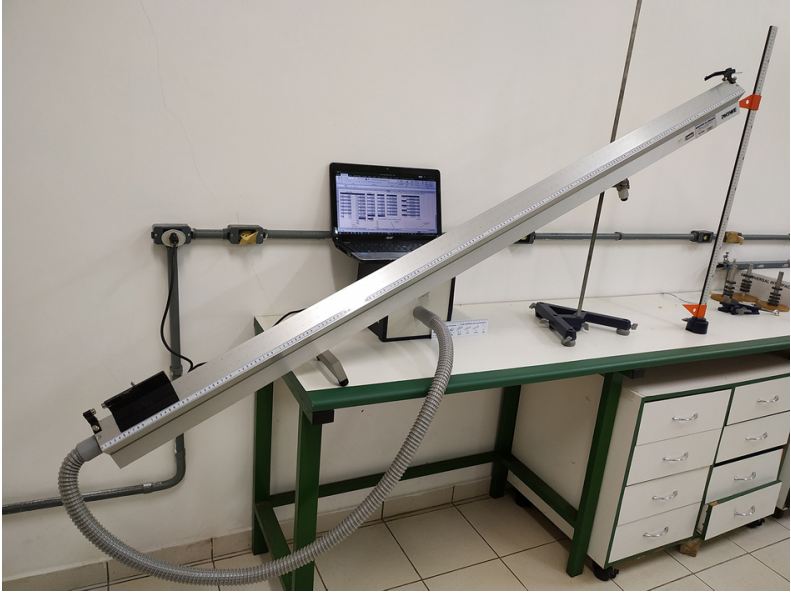

Figura 12: Montagem experimental para realização da terceira atividade.

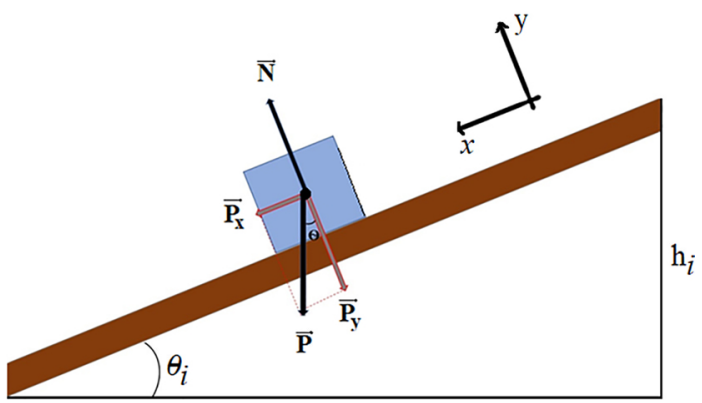

Figura 13: Esquema para obter a altura necessária para determinados ângulos previamente escolhidos.

Cada $\theta_{i}$ escolhido está relacionado com uma altura $h_{i}$ que é, na realidade, o cateto oposto ao ângulo $\theta_{i}$. Da Figura 13, vemos que os ângulos $\theta_{i}$ 's podem ser obtidos por

$$
\sin \theta_{i}=\frac{h_{i}}{1,5}
$$

em que 1,5 é a hipotenusa, considerada do pé de apoio do trilho até a extremidade oposta ao ímã.

Depois de posicionado o trilho de ar em um $\theta_{i}$ específico, medimos a distância entre os ímãs. Este procedimento foi repetido por diversas vezes para ângulos distintos (Figura 14).

Neste último caso, consideramos também o equilíbrio estático, ou seja, $\vec{P}_{x}+\vec{F}_{M}=\overrightarrow{0}$, fornecendo $\left|\vec{P}_{x}\right|=\left|\vec{F}_{M}\right|$. Assim, o objetivo da atividade é fornecer a relação entre a força magnética e a distância entre os ímãs.

Por fim, realizamos as mesmas atividades com o segundo par de ímãs, cujas dimensões já foram descritas na Tabela 1

Encerramos assim as atividades experimentais. Os dados coletados nos experimentos estão expressos nas tabelas da próxima Seção, para tratamento e discussão dos mesmos.

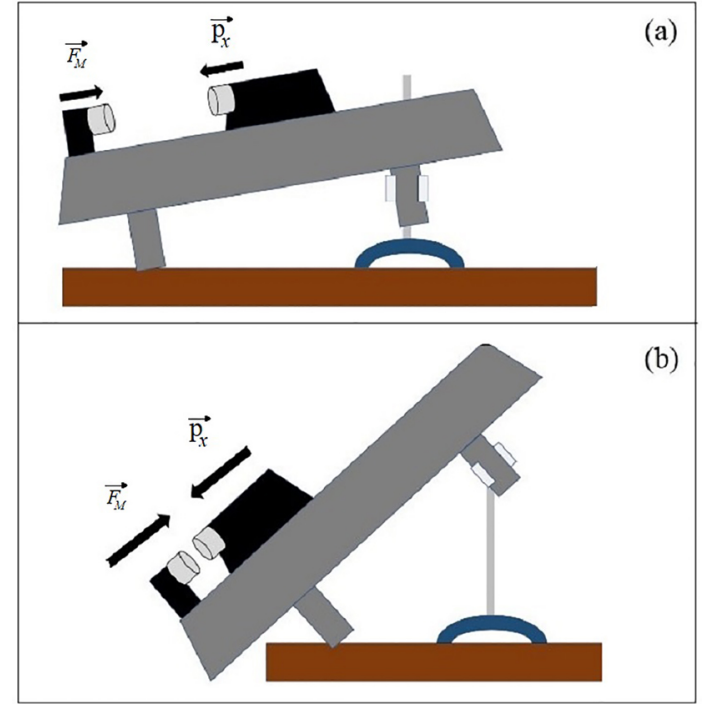

Figura 14: Esquema ilustrativo da terceira atividade.

\subsection{Validação estatística do modelo}

Um modelo para ser dito consistente, precisa passar por um crivo estatístico extremamente rigoroso. A validação do modelo nada mais é do que o teste de desempenho do mesmo em outras situações.

Desta forma, a validação de um modelo passa por determinados testes, aferidos por índices estatísticos. Para este fim, é preciso um conjunto de dados observados e as condições iniciais e de contorno para a verificação de quão bom é o desempenho do modelo. Dentre estes índices estatísticos, temos:

1. Coeficiente de Eficiência $(\varepsilon)$

$$
\varepsilon=1-\frac{\sum_{i=1}^{n}\left(O_{i}-P_{i}\right)^{2}}{\sum_{i=1}^{n}\left(O_{i}-\bar{O}\right)^{2}},
$$

desenvolvido por [22].

Deste, o seu valor pode ser encontrado entre $-\infty$ e 1. Quanto mais próximo de 1 for o seu valor, mais eficaz é o modelo.

2. Índice de concordância de Willmott $(\mathcal{D})$

$$
\mathcal{D}=1-\frac{\sum_{i=1}^{n}\left(O_{i}-P_{i}\right)^{2}}{\sum_{i=1}^{n}\left(\left|P_{i}-\bar{O}\right|+\left|O_{i}-\bar{O}\right|\right)^{2}},
$$

desenvolvido e publicado por [23], seu valor pode estar entre 1 e 0 , sendo que quanto mais próximo de 1 for o valor de $\mathcal{D}$, melhor o desempenho do modelo.

As equações (31) e (32) serão utilizadas para validar o modelo proposto para cada par de ímãs, onde $O_{i}$ são os 
dados observados experimentalmente e $P_{i}$ são os valores estimados pelo modelo. $\bar{O}$ e $\bar{P}$ são as respectivas médias aritméticas observadas e estimadas. Além disso, destacamos que tais índices estatísticos, somados à análise gráfica são suficientes para inferir que os erros cometidos nas medições, não implicam em discrepâncias relevantes para o propósito deste trabalho.

\section{Resultados e Discussões}

A força de repulsão magnética entre os pares de ímãs, descritos neste manuscrito, está relacionada com a distância relativa entre eles de forma exponencial. Para resultados de força de atração entre ímãs de neodímio recomendamos a leitura das referências [18,19]. Como mencionado anteriormente, tal problema não é trivial mesmo se imaginarmos ímãs com geometria bem definida, magnetização uniforme e orientada segundo um eixo de simetria específico.

\subsection{Par de ímãs $12,7 \times 6,35 \mathrm{~mm}$}

A Tabela 2 apresenta as distâncias entre os ímãs devido às respectivas forças, obtidas nas três atividades realizadas.

Com os valores obtidos, verificamos que a parametrização mais simples, e que melhor se ajusta aos dados experimentais de todas as atividades realizadas neste trabalho, é a do tipo

$$
F(d)=\alpha_{i} e^{\beta_{i} d}
$$

onde $\alpha_{i}$ e $\beta_{i}$ são constantes a determinar, cujas unidades de medidas são dadas em $[\mathrm{N}]$ e $\left[m^{-1}\right]$, respectivamente.

A parametrização foi ajustada pela função nls() embutida no software R na versão 3.6.1 com interface RStudio 24 .

Na Atividade 1, devido ao equilíbrio estático, encaramos a igualdade, em módulo, entre as forças peso, $F_{P}$, e magnética, $F_{M}$. Desta forma, da Tabela 2 temos que

$$
F_{M}^{(1)}(d)=10,54 e^{-156,64 d} .
$$

De modo análogo, obtemos

$$
F_{M}^{(2)}(d)=7,39 e^{-136,17 d},
$$

para a Atividade 2, e

$$
F_{M}^{(3)}(d)=8,08 e^{-140,37 d} .
$$

para a Atividade 3 .

O comportamento gráfico para cada atividade experimental realizada com o par de ímãs, está ilustrado na Figura 15

Olhando para as Equações (34), 35 e 36 notamos uma sutil dispersão em torno das médias para as cons- tantes $\alpha$ e $\beta$, de forma que,

$$
F_{M}^{(g)}(d)=(9 \pm 2) e^{-(14 \pm 1) 10 d},
$$

poderá ser interpretada como um modelo geral para descrever a interação magnética entre os ímãs em questão.

A dispersão que surge de uma atividade para outra, considerando este par de ímãs ou o outro, resulta das discrepâncias observacionais persistentes, tais como erros de paralaxe. O menor desalinhamento dos eixos de simetria dos ímãs geram também forças radiais, que poderiam comprometer os resultados.

A Figura 16 mostra que o modelo (Eq. (37) responde com excelente aproximação nas três atividades. Para as três atividades, notamos a partir do coeficiente de determinação, $R^{2}=0,99$, que os dados observados podem ser explicados em $99 \%$ pelo modelo.

Para corroborar este resultado, testamos a acurácia do modelo através dos índices estatísticos (Tabela 3 .

Assim, o modelo (Eq. (37) ) apresentou desempenho entre $97 \%$ e $99 \%$ quando comparados os valores preditos pela Eq. 37 com os esperados para a força magné-

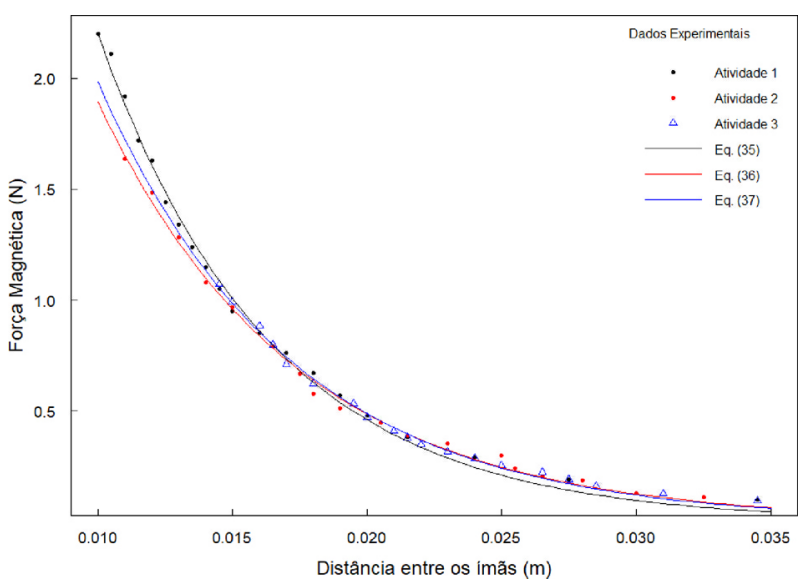

Figura 15: Força magnética em função da distância entre os ímãs, observada nas três atividades experimentais propostas.

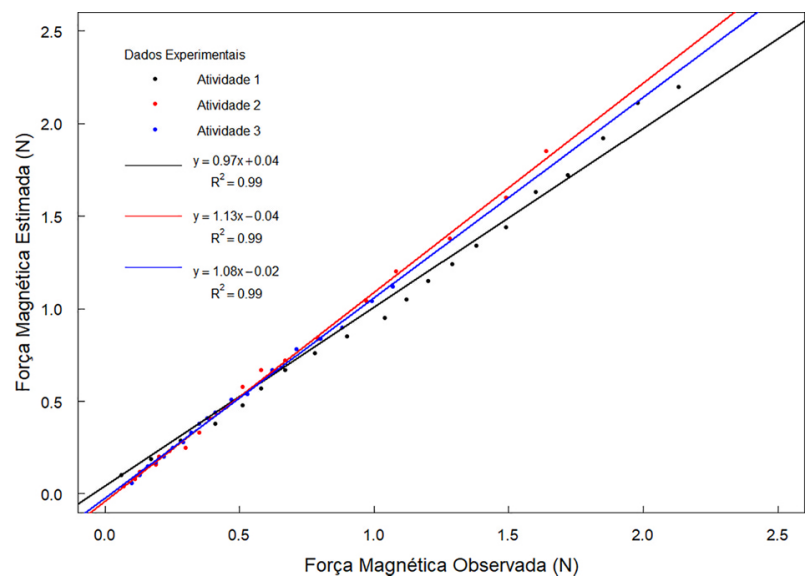

Figura 16: Força magnética estimada pelo modelo em função da força observada nas três atividades experimentais propostas. 
tica. Portanto, verifica-se que para pares de ímãs com as mesmas configurações utilizadas nesse estudo, o modelo proposto na Eq. (37) exibe valores satisfatórios.

\subsection{Par de ímãs $20,0 \times 6,0 \mathrm{~mm}$}

A Tabela 4 apresenta as distâncias entre os ímãs devido às respectivas forças, obtidas nos três experimentos realizados.

A curva ajustada a partir dos dados experimentais de cada atividade realizada, tem comportamento análogo ao da Eq. (33). Neste caso, $\alpha_{i}$ e $\beta_{i}$ admitirão valores distintos daqueles obtidos anteriormente. De fato, a geometria entre os pares de ímãs utilizados é distinta e, portanto, justifica a mudança nos valores dessas constantes.

Seguindo os mesmos procedimentos realizados com os ímãs menores, para este par de ímãs, obtivemos:

$$
\begin{gathered}
F_{M}^{(1)}(d)=15,86 e^{-103,44 d}, \\
F_{M}^{(2)}(d)=9,01 e^{-87,22 d}, \\
F_{M}^{(3)}(d)=12,26 e^{-93,71 d},
\end{gathered}
$$

para as Atividades 1, 2 e 3, respectivamente.

Tabela 3: Índices estatísticos para validação do modelo (Eq. (37)): $\varepsilon$ é o coeficiente de eficiência e $\mathcal{D}$ é o índice de concordância de Willmott.

\begin{tabular}{cccc}
\hline Índices & Atividade 1 & Atividade 2 & Atividade 3 \\
\hline$\varepsilon$ & 0,99 & 0,97 & 0,99 \\
$d$ & 0,99 & 0,99 & 0,99 \\
\hline
\end{tabular}

Tabela 4: Valores observados nas três atividades experimentais.

\begin{tabular}{cc|cc|cc}
\hline \multicolumn{2}{c}{ Atividade 1} & \multicolumn{2}{c}{ Atividade 2} & \multicolumn{2}{c}{ Atividade 3} \\
\hline$d(\mathrm{~m})$ & $F_{P}(\mathrm{~N})$ & $d(\mathrm{~m})$ & $F_{E}(\mathrm{~N})$ & $d(\mathrm{~m})$ & $F_{x}(\mathrm{~N})$ \\
\hline 0,0560 & 0,10 & 0,0840 & 0,009 & 0,0505 & 0,150 \\
0,0460 & 0,19 & 0,0740 & 0,019 & 0,0455 & 0,200 \\
0,0405 & 0,29 & 0,0630 & 0,056 & 0,0420 & 0,250 \\
0,0370 & 0,38 & 0,0580 & 0,075 & 0,0400 & 0,300 \\
0,0340 & 0,48 & 0,0530 & 0,103 & 0,0380 & 0,350 \\
0,0320 & 0,57 & 0,0485 & 0,150 & 0,0360 & 0,399 \\
0,0300 & 0,67 & 0,0460 & 0,169 & 0,0350 & 0,449 \\
0,0290 & 0,76 & 0,0435 & 0,225 & 0,0340 & 0,498 \\
0,0280 & 0,86 & 0,0410 & 0,263 & 0,0330 & 0,548 \\
0,0270 & 0,95 & 0,0395 & 0,301 & 0,0320 & 0,597 \\
0,0260 & 1,04 & 0,0360 & 0,376 & 0,0310 & 0,646 \\
0,0255 & 1,15 & 0,0335 & 0,470 & 0,0300 & 0,743 \\
0,0250 & 1,24 & 0,0320 & 0,564 & 0,0285 & 0,839 \\
0,0240 & 1,34 & 0,0310 & 0,629 & 0,0270 & 0,982 \\
0,0230 & 1,44 & 0,0300 & 0,695 & 0,0255 & 1,121 \\
0,0225 & 1,53 & 0,0290 & 0,761 & 0,0245 & 1,258 \\
0,0220 & 1,62 & 0,0280 & 0,789 & 0,0235 & 1,391 \\
0,0215 & 1,73 & 0,0270 & 0,827 & 0,0220 & 1,563 \\
0,0210 & 1,82 & 0,0260 & 0,874 & 0,0210 & 1,687 \\
0,0205 & 1,92 & 0,0250 & 0,940 & $\ldots$ & $\ldots$ \\
0,0200 & 2,01 & 0,0240 & 1,071 & $\ldots$ & $\ldots$ \\
$\ldots$ & $\ldots$ & 0,0230 & 1,165 & $\ldots$ & $\ldots$ \\
$\ldots$ & $\ldots$ & 0,0220 & 1,353 & $\ldots$ & $\ldots$ \\
$\cdots$ & $\ldots$ & 0,0210 & 1,541 & $\ldots$ & $\ldots$ \\
\hline
\end{tabular}

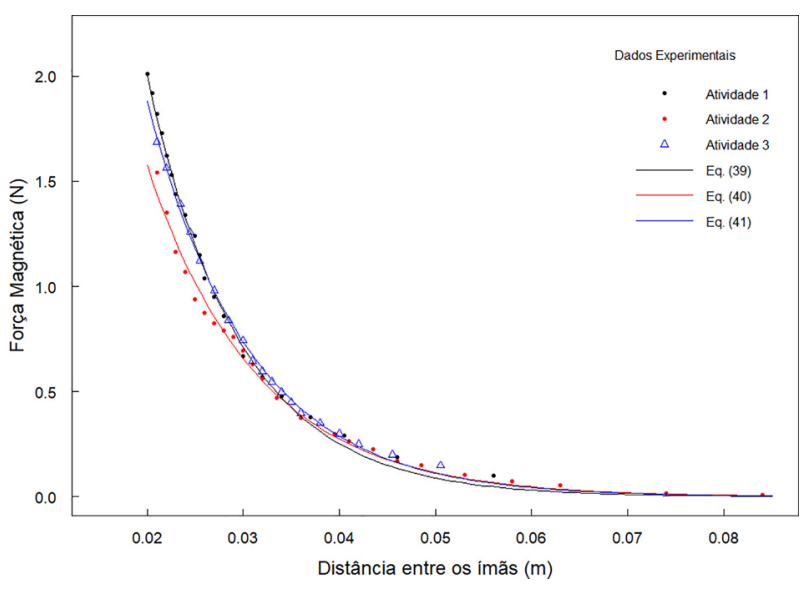

Figura 17: Força magnética em função da distância entre os ímãs, observada nas três atividades experimentais propostas.

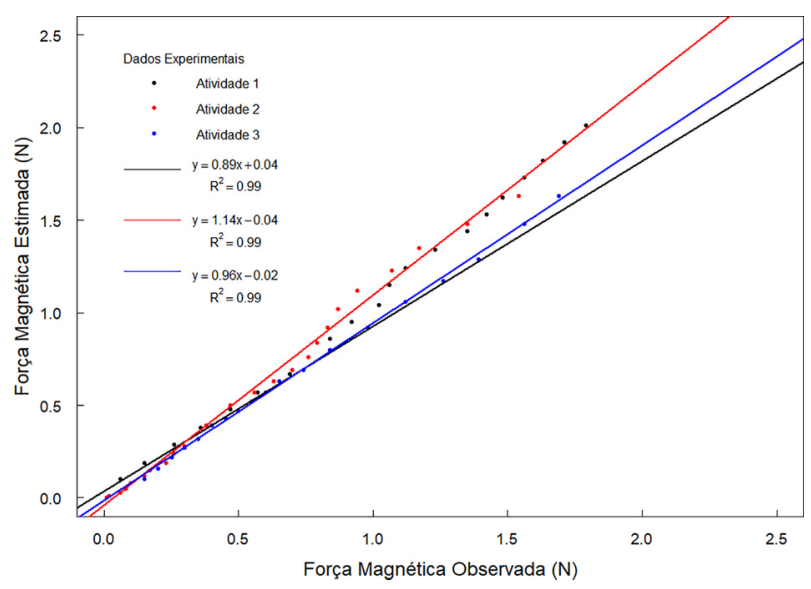

Figura 18: Força magnética estimada pelo modelo em função da força observada nas três atividades experimentais propostas.

A curva obtida para cada atividade experimental realizada com o segundo par de ímãs, está ilustrado na Figura 17

Da mesma forma, podemos escrever uma equação dada por

$$
F_{M}^{(g)}(d)=(12 \pm 3) e^{-(95 \pm 8) d}
$$

e que pode ser interpretada como um modelo geral para descrever a interação magnética entre o par de ímãs utilizados nesta etapa.

De fato, o modelo dado pela Eq. 41 é capaz de explicar, com excelente aproximação, os valores observados nas três atividades. Isto está ilustrado na Figura 18 onde são exibidos os coeficientes de determinação das regressões lineares.

A acurácia do modelo (Eq. 41) está descrita na Tabela 5 onde estão apresentados os índices estatísticos para validação do modelo.

Desta forma, o modelo (Eq. (41)) apresentou desempenho entre $97 \%$ e $99 \%$ quando comparados os valores preditos pela Eq. (41) com os esperados para a força magnética. Portanto, verifica-se que para pares de ímãs com 
Tabela 5: O coeficiente de eficiência $(\varepsilon)$ e o índice de concordância de Willmott $(\mathcal{D})$ para validação do modelo (Eq. (41)).

\begin{tabular}{cccc}
\hline Índices & Atividade 1 & Atividade 2 & Atividade 3 \\
\hline$\varepsilon$ & 0,97 & 0,97 & 0,99 \\
$d$ & 0,99 & 0,99 & 0,99
\end{tabular}

as mesmas propriedades utilizadas nesse estudo, o modelo proposto na Eq. 41) apresenta excelentes resultados.

\section{Conclusão}

Este trabalho apresentou aspectos distintos ligados ao magnetismo e interações magnéticas. O texto foi composto por duas partes independentes, uma teórica e outra experimental, sendo que nossos dois resultados principais são:

i. Na primeira parte, apresentamos uma construção alternativa para a descrição de campos magnéticos. Tal formulação é restrita ao caso em que partículas carregadas sofrem a ação de força quando atravessam uma região espacial permeada por um campo magnético. Nosso trabalho indica, a partir da experimentação, como o campo magnético representado por um tensor antissimétrico do tipo $(1,1)$ pode ser descrito por um vetor axial. Parte da dedução pode ser encarada como uma aplicação direta do princípio da relatividade, veja (11) e $(13)$. Embora restrita à interação entre partículas carregadas movendo-se em um campo magnético, acreditamos que tal construção de fundamentos tem forte potencial pedagógico, evitando saltos conceituais, como por exemplo, encarar um campo magnético como um vetor, sem a devida justificativa.

ii. Aliado ao setor epistemológico inicial deste artigo, embora de maneira independente deste, apresentamos também um lado mais pragmático, sendo este o nosso principal resultado. Propusemos uma sequência de atividades experimentais para estimar a força (de repulsão) entre dois ímãs cilíndricos permanentes iguais (de magnetização uniforme e paralela ao eixo axial de cada ímã). As atividades são de simples montagem e execução e podem ser propostas em diferentes níveis (do ensino médio ao superior). Não podemos menosprezar a simplicidade dos experimentos se levarmos em conta a situação precária de diversas escolas de ensino básico do país. Talvez este seja exatamente um trunfo para o professor motivar e engajar seus estudantes, ao aliar, por exemplo, modelagem matemática de um problema moderno com diferentes aplicações tecnológicas.

Mostramos como, para ímãs cilíndricos iguais, a força admite uma representação analítica de decaimento exponencial com a distância (gap axial) entre os mesmos. A forma exata da força correspondente foi apresentada a critério de comparação, veja a expressão (27). Notavelmente, tal expressão depende fortemente da geometria dos ímãs. Nosso modelo efetivo, de decaimento exponencial em 28, parece prever, de maneira implícita, tal dependência. De fato, as constantes $\alpha_{i}$ e $\beta_{i}$ em (37) e (41) diferem consideravelmente, reforçando este ponto. Naturalmente as constantes dependem também da magnetização $M_{0}$ de cada ímã.

Assim, diante dos nossos resultados, uma proposta didática nesse sentido é mais que justificável.

\section{Referências}

[1] H.M. Nussenzveig, Curso de Física Básica: Eletromagnetismo (Editora Edgard Blücher, São Paulo, 2013).

[2] D. Griffiths, Introduction to Electrodynamics (Prentice Hall, Upper Saddle River, 1999).

[3] R.R.D. Halliday e J. Walker, Fundamentos de Fúsica: Eletromagnetismo (Editora LTC, Rio de Janeiro, 2016).

[4] A.N. Rocha, B.F. Rizzuti e D.S. Mota, Revista Brasileira de Ensino de Física 35, 434 (2013).

[5] B. Lesche, Teoria da Relatividade (Editora Livraria da Física, São Paulo, 2005).

[6] R.P. Feynman, R.B. Leighton e M.L. Sands, The Feynman lectures on physics (Basic Books, New York, 2011).

[7] J. Bernstein, Albert Einstein and the frontiers of physics (Oxford University Press, Oxford, 1996).

[8] J.S.M. Ruan e C.B. Wheeler, Sensors and Actuators A 91, 346 (2001).

[9] I.J. Busch-Vishniac, Sensors e Actuators A 33, 207 (1992).

[10] J.S. Agashe e D.P. Arnold, Journal of Physics D: Applied Physics 41, 105001 (2008)

[11] https://www.ufjf.br/fisica/teste/notas-deaulas/bernhard-johannes-lesche/fisica-iii/, acessado em 21/05/2020.

[12] J.J. Thomson, Philosophical Magazine 44, 293 (1897).

[13] L.M. Gaio, D.R.T. de Barros e B.F. Rizzuti, Revista Brasileira de Ensino Física 41, e20180295 (2019).

[14] J.R. Melcher, Continuum Electromechanics (MIT Press, Cambridge, 1981)

[15] S. Tandon, M. Beleggia, Y. Zhu e M.D. Graef, Journal of Magnetism and Magnetic Materials 271, 9 (2004).

[16] S. Tandon, M. Beleggia, Y. Zhu e M.D. Graef, Journal of Magnetism and Magnetic Materials 27127 (2004).

[17] M. Beleggia, S. Tandon, Y. Zhu e M.D. Graef, Journal of Magnetism and Magnetic Materials 278, 270 (2004).

[18] D. Vokoun, G. Tomassetti, M. Beleggia e I. Stachiv, Journal of Magnetism and Magnetic Materials 323, 55 (2011).

[19] D. Vokoun, M. Beleggia, L. Heller e P. Šittner, Journal of magnetism and Magnetic Materials 321, 3758 (2009).

[20] H.M. Nussenzveig, Curso de Física Básica: Mecânica (Editora Edgard Blücher, São Paulo, 2013).

[21] A.A.G. Campos, E.S. Alves e N.L. Speziali, Física Experimental Básica na Universidade (Editora UFMG, Belo Horizonte, 2018).

[22] J.E. Nash e J.V. Sutcliffe, Journal of hydrology 10, 282 (1970).

[23] C.J. Willmott, Bulletin of the American Meteorological Society 63, 1309 (1982).

[24] R Core Team, acessado em 20/12/2019: https://www r-project.org/about.html. 